\title{
Development of in-Home Wireless Continuous Temperature Data Logging and Alarming System for Fever Monitoring in Pediatrics
}

\author{
Ali S. Al-Mejrad \\ Department of Clinical Laboratory Sciences, Faculty of Applied Medical Sciences University of Hail, Hail, \\ Kingdom of Saudi Arabia. \\ E-Mail:a.almejrad@uoh.edu.sa
}

\begin{abstract}
Fever is one of the most common concern to be taken care by parents that sometimes force them to bring their child to the hospital emergency for continuous follow up especially at night when sleeping. Fever is defined when a rectal temperature reaches over 38.0 C $(100.4 \mathrm{~F})$. Temperatures measured from other sites of body are usually less. There is no defined threshold for fever due to variation of body temperatures between different individuals as much as $1 \mathrm{~F}$. Fever itself is not life threatening unless the rectal temperature is persistent over than $41.6 \mathrm{C}(107 \mathrm{~F})$. Fever may be due to a serious illness and usually is caused by common infections that are not serious. However, a fever can be caused by other causes other than infections. Since continuous temperature monitoring is inapplicable at the rectal site, the paper aims at developing a prototype system using Wireless Sensor Network (WSN) for wireless continuous fever monitoring system from the head skin or wrist that are the most applicable area even so one must add 2 degrees for the read temperature correction. The system can record the temperature at the patient terminal and transmit the fever status and critical situations to an alarming system in the side of taking-care people that will help in in-home care for pediatrics suffering from fever.
\end{abstract}

Keywords: Wireless; Temperature monitoring; data logging; alarming system.

\section{Introduction}

Fever is one of the most important symptom of many diseases. Fever may be due to a serious illness and usually is caused by common infections that are not serious. However, a fever can be caused by other causes other than infections. The body's temperature increase is controlled by the part of the brain called the hypothalamus to fight the infection that may reach the fever level. Fever is considered one of the most common concern to be taken care by parents that sometimes force them to bring their child to the hospital emergency for continuous follow up especially at night when sleeping. Fever is defined when a rectal temperature reaches over 38.0 C (100.4 F). Temperatures measured from other sites of body are usually less. There is no defined threshold for fever due to variation of body temperatures between different individuals as much as $1 \mathrm{~F}$. Fever itself is not life threatening unless the rectal temperature is persistent over than 41.6 C (107 F) [1][2].

In the past, body temperature monitoring was using a thermometer constructed of glass filled with mercury. "However, the American Academy of Pediatrics
(AAP) recommends against using mercury thermometers because the glass can break, and mercury is poisonous [3]". In addition, this kind of thermometer can work with adult and cannot be used properly with infant even at the rectal site. The most commonly used and recommended are Electronic thermometers with a digital temperature readout display. Another type of thermometers is the plastic strip that change color to indicate the temperature. This type is the least accurate. The strip is used by placing it on the forehead and after one minute, the temperature can be read while the strip is in its place. Another type of plastic strip thermometer is used for the mouth. Hence, there are many kinds of temperature measurement methods but most of it is inconvenient to infants and child monitoring, because monitoring means continuous reading of the temperature [4].

Therefore, a method for continuous temperature monitoring has to be developed to be used in home and still be safe and convenient [5]. This method will enable a continuous read out of the temperature data utilizing the wireless technology from multiple transmitter node that enable the person on charge to monitor the temperature of many patients (infant, and 
child). This paper aims at developing a prototype system using embedded technology and Wireless Sensor Network (WSN) technology for wireless continuous fever monitoring system from the head skin or wrist that are the most applicable area taking in consideration adding 2 degree for the read temperature correction [6]. The wireless temperature monitoring system (WTMS) provides 24/7 continuous temperature monitoring of critical patient (Infant, and Child). Continuous monitoring provides the means to detect abnormalities (fever) at an early stage. Utilizing wireless technology eliminates the need for cabling. WTMS allows for easy field data collection. Temperature data is transmitted from the sensor at the transmitter node to a nearby receiver node via wireless connection. The receiver node can be connected to a computer via USB. In addition, the receiver node can work standalone without the PC. A universal receiver node can be utilized as a data logger that can collect data from any transmitter node. This universal receiver and the attached PC can work to trigger visual and/or audible alarm for preset temperature values for fever detection even more it can send SMS to the smart phone belonging to the person in charge such as parents. In addition to that, the data can be analyzed later for diagnosis and reported by a dedicated software package.

\section{System Development}

\subsection{Hardware and System Block Diagram}

The temperature wireless system designed consists of:
A. Transmitter Node
B. Receiver Node
C. Data Access Module

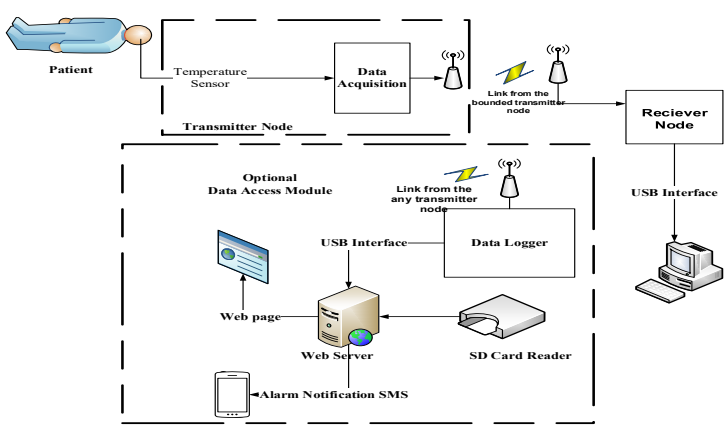

Figure 1. System Block Diagram
Fig. 1 shows a general block diagram of a wireless temperature monitoring system (WTMS). The system consists of three major parts: transmitter node, receiver node, and optional data access module.

\section{A. Transmitter Node}

The system is comprised of Wireless transmitter node that consists of a power subsystem (battery), temperature sensor, and data acquisition. This module is based on wireless Wi-Fi technology. This module is designed to operate in moisture environment and is protected by adding moisture resist material that will protect and isolate the patient from being connected to the circuit via moisture. The transmitter node has a lead off detector to trigger an alarm on the receiver node when there is no or bad contact on the patient skin. The transmitter is attached to the patient skin all the time by the mean of head bandage or wrist strap that will give the patient a convenient way of every day practice. Figure 2 shows the transmitter node, which consists of temperature sensor; lead off detector, microcontroller, battery, and the transmitting antenna.

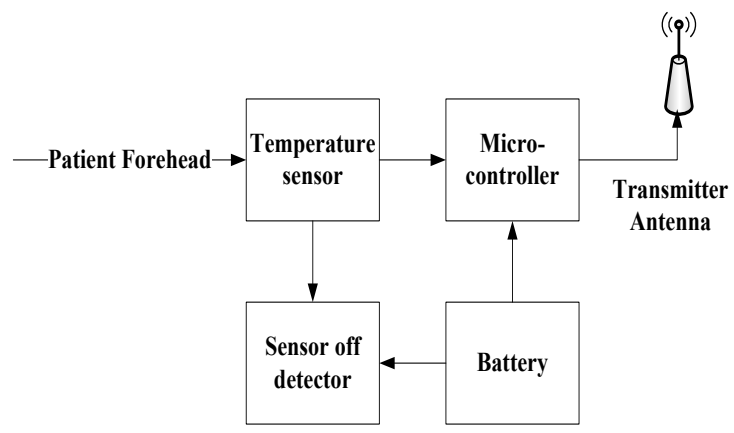

Figure 2. Transmitter Node

\section{B. Receiver Node}

It consists of a power subsystem (battery and battery management; recharge circuit operate from USB port), and readout device (LCD). This module is based on wireless Wi-Fi technology that can be directly connected to the PC via USB for data collection and further analysis. The receiver node contains audible and visual alarms, and data storage unit (SD card). Any receiver node can be programmed to collect data from many transmitters, as the case when there are many children or infants to be monitored for temperature rise. The receiver contains SD card to store the data for further analysis by physicians. The collected data can be sent to physician over the internet under user control when the receiver node is connected to a PC. Figure 3 shows the receiver node, which 
consists of receiving antenna, microcontroller which control: LCD as a reading out device for the temperature and alarm values, buzzer for audible alarm, mass storage (I2C EEPROM, and SD card). The controller has a USB interfacing capability to the $\mathrm{PC}$ in order to collect the data for further analysis. In addition, the receiver node battery could be charged from the PC USB port.

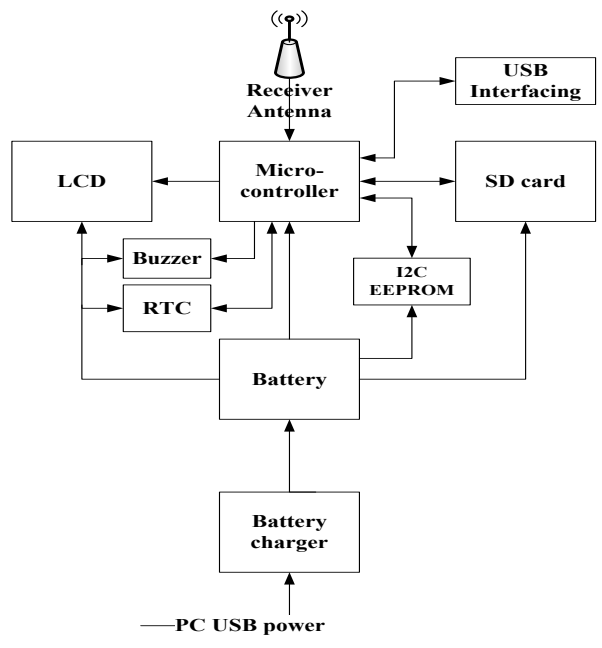

Figure 3. Receiver Node

\section{Data access module}

It consists of data logger module which can be connected to the PC or a web server for data distribution over the web, sending alarm notification SMS to smart phones. SD card reader can be connected to the server for reading SD card from any receiver. The data logger can connect to any transmitter node(s) for data collection and analysis. The data logger is mainly powered from the PC USB port.

\subsection{Software and User Interface}

A user interface is developed using Laboratory Virtual Instrument Engineering Workbench to control the wireless module and collect the temperature data of patient events of high temperature threshold of fever as shown in Figure 4 [7].

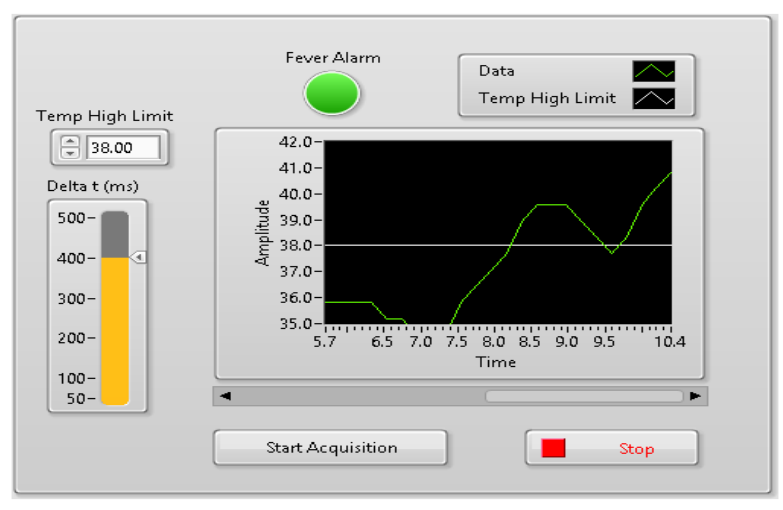

Figure 4. Front Panel of the User Interface of Temperature Data Collection and Fever Alarms Events

\section{Results and Discussion}

\section{Analysis of Body Temperature Measurements Comparison Test}

Testing the sensor DS18B20 as body temperature sensor is done with comparison to the measurement results with mercury thermometer. The selection of this type of thermometer is due to its accuracy compared to other types of thermometers. Table 1 below shows the comparison results, the measurement difference and the average measurement error.

\begin{tabular}{|c|c|c|c|}
\hline No. & $\begin{array}{c}\text { Temperature } \\
\text { Sensor } \\
\left({ }^{0} \mathrm{C}\right)\end{array}$ & $\begin{array}{c}\text { Mercury } \\
\text { Thermometer } \\
\left({ }^{0} \mathrm{C}\right)\end{array}$ & $\begin{array}{c}\text { Measurement } \\
\text { Difference } \\
\left({ }^{0} \mathrm{C}\right)\end{array}$ \\
\hline 1 & 36.75 & 37.60 & 0.85 \\
\hline 2 & 36.63 & 37.25 & 0.62 \\
\hline 3 & 36.25 & 36.97 & 0.72 \\
\hline 4 & 36.35 & 36.94 & 0.59 \\
\hline 5 & 36.56 & 37.25 & 0.69 \\
\hline 6 & 36.06 & 36.70 & 0.64 \\
\hline 7 & 35.95 & 36.49 & 0.54 \\
\hline 8 & 36.85 & 37.28 & 0.43 \\
\hline 9 & 36.75 & 37.57 & 0.82 \\
\hline 10 & 36.70 & 37.53 & 0.83 \\
\hline 11 & 36.50 & 37.30 & 0.80 \\
\hline 12 & 36.53 & 37.16 & 0.63 \\
\hline 13 & 36.54 & 36.96 & 0.42 \\
\hline 14 & 36.26 & 36.71 & 0.45 \\
\hline 15 & 36.23 & 36.75 & 0.52 \\
\hline & Average - Error & $0.64 \%$ \\
\hline
\end{tabular}

Table 1. Body temperature test results 
From the test results, obtained results showed the temperature has an average error around $0.64 \%$ using the Mercury Thermometer compared to the developed system. Therefore, it can be stated that the sensor reading $\mathrm{s}$ are very good.

\section{Analysis of Events of High Temperature Threshold of Fever Test}

From the test results of some of collected temperature data shown in Table 2 which gives continuous monitoring for critical events of fever (as shown in RED colors ), and alarming system to prevent deterioration of the patient condition

\begin{tabular}{|c|c|c|c|c|c|}
\hline No & $\begin{array}{l}\text { Time } \\
\text { Data }\end{array}$ & $\begin{array}{l}\text { Temp } \\
\text { Data }\end{array}$ & $\begin{array}{c}\text { Time } \\
\text { Temp } \\
\text { High } \\
\text { Limit }\end{array}$ & $\begin{array}{l}\text { Temp } \\
\text { High } \\
\text { Limit }\end{array}$ & $\begin{array}{c}\text { Events of } \\
\text { Alarms } \\
\text { (in RED) }\end{array}$ \\
\hline 1 & 5.7 & 35.8 & 5.7 & 38 & \\
\hline 2 & 5.9 & 35.8 & 5.9 & 38 & \\
\hline 3 & 6.1 & 35.8 & 6.1 & 38 & \\
\hline 4 & 6.3 & 35.8 & 6.3 & 38 & \\
\hline 5 & 6.5 & 35.2 & 6.5 & 38 & \\
\hline 6 & 6.7 & 35.2 & 6.7 & 38 & \\
\hline 7 & 6.9 & 34.6 & 6.9 & 38 & \\
\hline 8 & 7.1 & 34.6 & 7.1 & 38 & \\
\hline 9 & 8.4 & 38.9 & 8.4 & 38 & FEVER \\
\hline 10 & 8.6 & 39.6 & 8.6 & 38 & FEVER \\
\hline 11 & 8.8 & 39.6 & 8.8 & 38 & FEVER \\
\hline 12 & 9 & 39.6 & 9 & 38 & FEVER \\
\hline 13 & 9.2 & 38.9 & 9.2 & 38 & FEVER \\
\hline 14 & 9.4 & 38.3 & 9.4 & 38 & FEVER \\
\hline 20 & 9.6 & 37.7 & 9.6 & 38 & \\
\hline
\end{tabular}

Table 2. Events of High Temperature Threshold of Fever Test Results

\section{Analysis of Data Transmission Performance Test}

From the test results of this communication between the master module and the slave, the slave module used can accept data from master module according to data delivered.

The performance test of Nodemcu ESP8266 works to find out if the sensor is accessible by other devices with a certain distance. Testing is done by sending data on Nodemcu ESP8266 to display the results on the website and then test access with a certain range. Distance parameter of the maximal use range is about 50 meters. From the tests that have been done, it can be concluded that the website is inaccessible in the range above 50 meters. One of the most important factors that affect the process of access and delivery of the data is indoor so possible transmitted signals will be hindered and cannot be well reached.

\section{Conclusion and Future Work}

The designed system goal is to provide in home, selfdependent, continuous monitoring for critical events, and alarming system to prevent deterioration of the patient condition. The system has many features with wireless (Wi-Fi) connectivity in range of up to 50 meter (the distance between the transmitter and receiver nodes), typical signal reception of once every 1-10 minutes under user control, frequency of data transmission increases with fast temperature rise, temperature range $25^{\circ} \mathrm{C}$ to $50{ }^{\circ} \mathrm{C}$ with $0.1{ }^{\circ} \mathrm{C}$ resolution, preset alarm values, moisture resistant for humid environments.

\section{Acknowledgement}

I like to thank the Deanship of Scientific Research of University of Hail, for their support of my research.

\section{References}

1- Herzog LW and Coyne LJ., "What is fever? Normal temperature in infants less than 3 months old", Clin Pediatr, 32, pp.142-6, 1993.

2- Teach SJ and Fleisher GR., "Duration of fever and its relationship to bacteremia in febrile outpatients three to 36 months old", The Occult Bacteremia Study Group. Pediatr Emerg Care, 13, pp. 317-9, 1997.

3- Lynn R. Goldman, Michael W. Shannon and the Committee on Environmental Health, "Technical Report: Mercury in the Environment: Implications for Pediatricians, Pediatrics", Vol. 108 No. 1, pp. 197205, 2001.

4- Kyriacou P. A., "Temperature sensor technology", Biomedical Sensors, pp. 1-38, 2010.

5- IEC 60601-1, Medical Electrical Equipment- Part I: General Requirements for Safety and Essential Performance, International Electrotechnical Commission, Geneva, Clause 8.7,1995.

6- A. Tzavaras, and B. Spyropoulos, “ Development of a low-cost wireless monitoring System supporting the Continuity of Medical Care of the Patient at home", 35th Annual International Conference of the IEEE EMBS Osaka, Japan, 3 - 7 July, 2013.

7- Mehta B. et al. "Real Time Patient Tele- monitoring System Using LabVIEW", International Journal of Scientific \& Engineering Research (IJSER), Volume 3, Issue 4, April-2012. 